\title{
Changing profile of joint disorders with age: findings from a postal survey of the population of Calderdale, West Yorkshire, United Kingdom
}

\author{
Elizabeth M Badley, Alan Tennant
}

\begin{abstract}
A survey of the age-sex specific prevalence of joint problems in a population and associated features such as disablement and use of treatment was carried out in 1986 in Calderdale, West Yorkshire, United Kingdom. A postal questionnaire was sent to 25168 households; $87 \%$ were returned, representing households containing 42826 people aged 16 years and over. Positive answers to a question about pain, swelling, or stiffness in the joints, neck, or back were given by 10246 subjects, $24 \%$ of the population aged 16 years and older, of whom $6181(60.3 \%)$ were women. The rate of reporting of joint problems increased markedly with age, from 5\% for subjects aged 16-24 years to $54 \%$ for those aged 85 years and older. The joint sites most often reported as affected were the knee and the back, with a frequency in the population of about $10 \%$. The increase in joint problems with age was accompanied by an increase in reported morning stiffness of more than half an hour, taking drugs, and disability, but not in reporting seeing a specialist for these conditions. Of those aged 85 years and older who reported joint problems, most also had difficulty or dependence in activities of daily living. The increasing prevalence of joint problems with age has implications for the provision of care, both in the community and in hospitals, especially in view of the aging of the population as a whole. The planning of health services for those with rheumatic disorders needs to take into account the high incidence of joint problems in the population.
\end{abstract}

University of Toronto Rheumatic Disease Unit, The Wellesley Hospital, 160 Wellesley Street East, Toronto, Ontario, Canada

Elizabeth M Badley

Rheumatology and

Rehabilitation

Research Unit,

University of Leeds,

36 Clarendon Road,

Leeds,

Yorkshire,

United Kingdom

Alan Tennant

Correspondence to:

Dr Elizabeth M Badley,

University of Toronto

Rheumatic Disease Unit,

Rheumatic Disease Unit,

160 Wellesley Street East,

Turner Wing,

Room 650,

Toronto,

Ontario M4Y 1J3,

Canada.

Accepted for publication 14 May 1991
Most studies have been about what might be considered to be established diagnostic groups. Although the increase in the prevalence of musculoskeletal disorders with age is found overall, the pattern is different for different disorders. Although the arthropathies increase with age, spinal conditions tend to have a peak prevalence in middle life. ${ }^{1513}$ Relatively few studies have considered the overall picture in terms of the pattern of joints affected.

A survey of disability in the population, which included a postal screening questionnaire asking about joint problems, has allowed us to examine the age-sex specific prevalence of joint symptoms in the population, and to study associated aspects such as the use of treatment and disablement in those reporting problems. This allows further consideration of the implications of an aging population for the provision of care in the community and in hospitals, including the potential need for specialist medical services.

\section{Methods}

A survey was carried out in 1986 in the population of Calderdale, West Yorkshire, United Kingdom. One of the three main objectives was to study the distribution of joint problems in the population. ${ }^{6}$ Calderdale is in the Pennines in the north of England, with a population at the 1981 census of 189402 . The demographic structure of Calderdale at the census, with $23 \%$ of its population aged under $16,61 \%$ aged $16-64,10 \%$ aged $65-74$, and $6 \%$ aged over 75 years, was virtually identical with that of England and Wales at that time.

A two stage methodology was used, similar to that in other surveys of disablement in the population. $^{714}$ The first stage consisted of a postal questionnaire to every third household in the area, using the domestic rating list as the sampling frame. The sample size was determined by the need to provide meaningful analysis for a rare group in the population, namely those very severely physically disabled aged 16-64 years, based on an estimate of 12 per 10000 people. $^{8}$

Screening questionnaires were sent to 25168 occupied dwellings in Calderdale and 21889 were returned, a response rate of $87 \%$. This was achieved by the original posting (first wave, $57 \%$ response), two further postal follow ups (second and third waves, taking the response to 73 and $81 \%$ respectively), and a final postal follow up (the fourth wave). The response represents 42826 people aged 16 years and older.

The four page screening questionnaire used in phase 1 elicited demographic characteristics of the household and information about subjects within the household who experienced disablement in selected activities of daily living as a 
Table 1 Reported joint problems in the Calderdale population by sex. The estimated number and percentage prevalence is given by age group (numbers in parentheses give the $95 \%$ confidence intervals $(C I)$ when added to and subtracted from the prevalence)

\begin{tabular}{|c|c|c|c|c|c|c|c|c|c|}
\hline & \multicolumn{9}{|c|}{ Age group (years) } \\
\hline & All ages & $16-24$ & $25-34$ & $35-44$ & $45-54$ & $55-64$ & $65-74$ & $75-84$ & $85+$ \\
\hline $\begin{array}{l}\text { Subjects* } \\
\text { Number } \\
\text { Prevalence } \\
\quad(95 \% \text { CI })(\%)\end{array}$ & $\begin{array}{l}10246 \\
23.9(0.4)\end{array}$ & $\begin{array}{l}350 \\
4.9(0.5)\end{array}$ & $\begin{array}{l}777 \\
10 \cdot 4(0 \cdot 7)\end{array}$ & $\begin{array}{l}1396 \\
20.1(0.9)\end{array}$ & $\stackrel{1621}{26 \cdot 0(1 \cdot 1)}$ & $\underset{37 \cdot 3(1 \cdot 2)}{2227}$ & $\begin{array}{l}2161 \\
39 \cdot 7(1 \cdot 3)\end{array}$ & $\begin{array}{l}1408 \\
45 \cdot 5(1 \cdot 8)\end{array}$ & $\stackrel{306}{53 \cdot 6}(4 \cdot 1)$ \\
\hline $\begin{array}{l}\text { Men } \\
\quad \text { Number } \\
\text { Prevalence } \\
\quad(95 \% \text { CI })(\%)\end{array}$ & $\begin{array}{l}4048 \\
20 \cdot 0(0 \cdot 4)\end{array}$ & $\begin{array}{l}134 \\
3.8(0.4)\end{array}$ & $\stackrel{371}{10 \cdot 0(0 \cdot 7)}$ & $\begin{array}{l}637 \\
19.7(0.9)\end{array}$ & $\stackrel{701}{23 \cdot 1(1 \cdot 0)}$ & $\begin{array}{l}953 \\
34 \cdot 3(1 \cdot 2)\end{array}$ & $\begin{array}{l}840 \\
35 \cdot 0(1 \cdot 3)\end{array}$ & $355.0(1 \cdot 7)$ & $\begin{array}{l}57 \\
39 \cdot 6(4 \cdot 0)\end{array}$ \\
\hline $\begin{array}{l}\text { Women } \\
\text { Number } \\
\text { Prevalence } \\
\quad(95 \% \text { CI })(\%)\end{array}$ & $\frac{6181}{27 \cdot 4(0 \cdot 4)}$ & $\underset{6 \cdot 1(0 \cdot 6)}{216}$ & $\begin{array}{l}406 \\
10 \cdot 7(0 \cdot 7)\end{array}$ & $\begin{array}{l}757 \\
22 \cdot 4(1 \cdot 0)\end{array}$ & $\frac{912}{28.5(1 \cdot 1)}$ & $\begin{array}{l}1272 \\
39 \cdot 9(1 \cdot 3)\end{array}$ & ${ }_{43.3(1 \cdot 3)}^{1318}$ & $\begin{array}{l}1051 \\
52 \cdot 1(1 \cdot 8)\end{array}$ & $\stackrel{249}{58 \cdot 3(4 \cdot 0)}$ \\
\hline
\end{tabular}

*Includes 17 subjects with unstated sex.

result of health problems or disabilities which were likely to continue. Disability questions asked about six activities of daily living which often cause difficulties for people with arthritis: getting up and down stairs; gripping or holding things or using arms, hands, or fingers; doing up buttons or zips; putting on shoes, socks, or stockings; brushing or combing hair; and getting out of a low chair. Dependence was defined as requiring help with four activities of daily living; getting in or out of bed, dressing, getting to and using the toilet, and getting out of the house. An enquiry was made about the nature of the main illness or cause of disability.

The questionnaire also asked 'does anyone in your household suffer from any pain, swelling or stiffness in their joints, neck or back?', and asked the number of people in the household who had joint problems. For each subject with problem joints the questionnaire asked for the site of the joints affected to be recorded on a chart. Eighteen possible joint sites were included: the neck, back, and left and right shoulder, elbow, wrist, hand or fingers, hip, knee, ankle, and foot or toes. No distinction was made between the type of joint problem experienced, nor between individual joints in the hands or fingers and feet or toes. No reference was made to the time period over

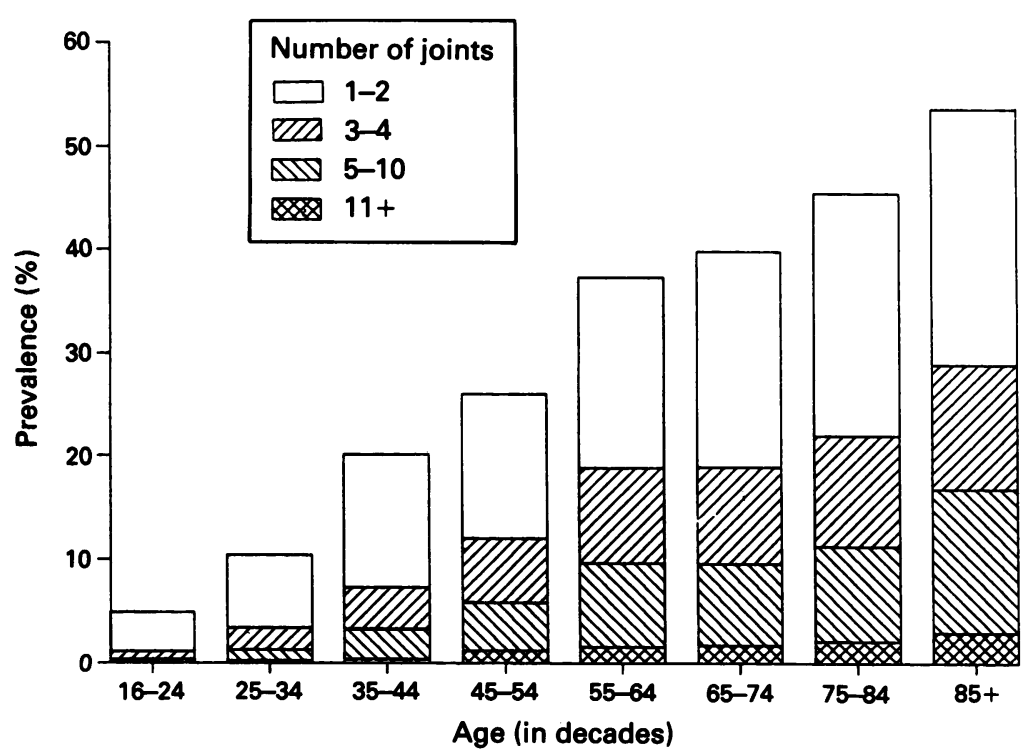

Figure 1 Prevalence of joint problems in the population, overall and for number of joints affected for 10 year age groups. which the joint problems had been experienced. Respondents were also asked to enter the cause of the joint problems, with 17 of the most common rheumatic disorders listed. Further questions asked about morning stiffness lasting for more than half an hour, whether anyone regularly took drugs because of problem joints, or had seen a hospital specialist because of these problems.

\section{Results}

Positive answers to the question about pain, swelling, or stiffness in the joints, neck or back were given by 10246 subjects, $24 \%$ of the population aged 16 years and older, of whom $6181(60 \cdot 3 \%)$ were women (table 1$)$. The rate of reporting of joint problems increased markedly with age (shown by non-overlapping confidence intervals (CI) for prevalence estimates), ranging from $4.9 \%(95 \%$ CI 4.4 to $5.4 \%)$ for ages $16-24$ years, to $53.6 \%(95 \%$ CI $49 \cdot 5$ to $57 \cdot 7 \%)$ for those aged 85 years and older. This increase was particularly marked for women. The increase in prevalence of joint problems with age was seen overall and for the number of joints affected (fig 1). The severity, as expressed by the number of joints reported, also increased with age; the prevalence of those reporting five or more joints affected increased significantly from $0.4 \%(95 \%$ CI 0.3 to $0.6 \%)$ of those aged $16-24$ years to $16 \cdot 8 \%(95 \%$ CI 13.8 to $19 \cdot 9 \%)$ of subjects aged 85 years or more. The overall median number of sites with joint problems was $1 \cdot 8$.

The joint sites most often reported as affected were the knee and the back, with a frequency in the population of around $10 \%$ (table 2). The shoulder, hand, neck, hip, foot, and ankle were less often reported and the wrist and elbow were the least often reported. The pattern of change in prevalence with age varied for different joint sites (table 2, fig 2). The pattern for the joints of the arms and legs is illustrated in fig 2A. The increase in prevalence with age was greatest for the knee, and less for the shoulder, hand, hip, ankle, and foot, which showed similar gradients. The change was least for the wrist and elbow. The back and neck showed an increasing prevalence in the 55-64 year old age group, then levelled out (fig 2B).

There was an increase with age in reported morning stiffness and regular taking of drugs for 
Table 2 Reported joint problems in the Calderdale population for individual joint sites. Estimated number and percentage prevalence by age group (numbers in parentheses give the $95 \%$ confidence intervals (CI) when added to and subtracted from the prevalence)

\begin{tabular}{|c|c|c|c|c|c|c|c|c|c|c|}
\hline \multirow{2}{*}{$\begin{array}{l}\text { Foint } \\
\text { affected }\end{array}$} & \multirow[t]{2}{*}{ Occurrence } & \multicolumn{9}{|c|}{ Age group (years) } \\
\hline & & All ages & $16-24$ & $25-34$ & $35-44$ & $45-54$ & $55-64$ & $65-74$ & $75-84$ & $85+$ \\
\hline \multirow{2}{*}{$\begin{array}{c}\text { Limb joints } \\
\text { Knee }\end{array}$} & & & & & & & & & & \\
\hline & $\begin{array}{l}\text { Number } \\
\text { Prevalence } \\
\text { (95\% CI) (\%) }\end{array}$ & $\begin{array}{l}4339 \\
\quad 10 \cdot 1(0 \cdot 3)\end{array}$ & $\stackrel{156}{2 \cdot 2(0 \cdot 3)}$ & $\begin{array}{l}283 \\
3.8(0 \cdot 4)\end{array}$ & $\begin{array}{l}459 \\
6.6(0.6)\end{array}$ & $\begin{array}{l}579 \\
9 \cdot 3(0 \cdot 7)\end{array}$ & $\begin{array}{l}970 \\
16 \cdot 8(1 \cdot 0)\end{array}$ & $\begin{array}{l}996 \\
18 \cdot 3(1 \cdot 0)\end{array}$ & $\stackrel{716}{23 \cdot 1(1 \cdot 5)}$ & $\begin{array}{l}180 \\
31 \cdot 5(3 \cdot 8)\end{array}$ \\
\hline Shoulder & $\begin{array}{l}\text { Number } \\
\text { Prevalence } \\
\text { (95\% CI) (\%) }\end{array}$ & $\begin{array}{l}2945 \\
6.9(0 \cdot 2)\end{array}$ & $\stackrel{47}{0 \cdot 7(0 \cdot 2)}$ & $\stackrel{170}{2 \cdot 3(0 \cdot 3)}$ & $\stackrel{378}{5.5(0.5)}$ & $\stackrel{511}{8 \cdot 2(0 \cdot 7)}$ & $\begin{array}{l}682 \\
11 \cdot 8(0 \cdot 8)\end{array}$ & $\begin{array}{l}659 \\
12 \cdot 1(0.9)\end{array}$ & $\begin{array}{l}407 \\
13 \cdot 2(1 \cdot 2)\end{array}$ & $\begin{array}{l}91 \\
15.9(3.0)\end{array}$ \\
\hline Hand & $\begin{array}{l}\text { Number } \\
\text { Prevalence } \\
\text { (95\% CI) (\%) }\end{array}$ & $\stackrel{2809}{6 \cdot 6(0.2)}$ & $\stackrel{38}{0 \cdot 5}(0 \cdot 2)$ & $\stackrel{148}{2 \cdot 0(0 \cdot 3)}$ & $\begin{array}{l}268 \\
3.9(0.5)\end{array}$ & $\begin{array}{l}398 \\
\quad 6.4(0.6)\end{array}$ & $\begin{array}{l}726 \\
12 \cdot 6(0 \cdot 9)\end{array}$ & $\begin{array}{l}674 \\
12 \cdot 4(0.9)\end{array}$ & $\begin{array}{l}447 \\
14 \cdot 4(1 \cdot 2)\end{array}$ & $\begin{array}{l}110 \\
19 \cdot 3(3 \cdot 2)\end{array}$ \\
\hline Hip & $\begin{array}{l}\text { Number } \\
\text { Prevalence } \\
\text { (95\% CI) (\%) }\end{array}$ & $\stackrel{2221}{5 \cdot 2(0 \cdot 2)}$ & ${ }_{0 \cdot 6(0 \cdot 2)}$ & $\stackrel{98}{1 \cdot 3(0 \cdot 3)}$ & $\stackrel{238}{3 \cdot 4(0 \cdot 4)}$ & $\begin{array}{l}380 \\
6 \cdot 1(0 \cdot 6)\end{array}$ & $\begin{array}{l}495 \\
\quad 8 \cdot 6(0 \cdot 7)\end{array}$ & $\begin{array}{l}537 \\
\quad 9.9(0.8)\end{array}$ & ${ }_{11}^{342} \cdot 1(1 \cdot 1)$ & $\begin{array}{l}86 \\
15 \cdot 1(2 \cdot 9)\end{array}$ \\
\hline Foot & $\begin{array}{l}\text { Number } \\
\text { Prevalence } \\
(95 \% \text { CI) (\%) }\end{array}$ & $\begin{array}{l}2050 \\
4 \cdot 8(0 \cdot 2)\end{array}$ & $\begin{array}{l}30 \\
0.4(0 \cdot 1)\end{array}$ & ${ }_{1 \cdot 1}^{80}(0 \cdot 2)$ & $\begin{array}{l}193 \\
2.8(0.4)\end{array}$ & $\begin{array}{l}331 \\
5 \cdot 3(0 \cdot 6)\end{array}$ & $\begin{array}{l}520 \\
9 \cdot 0(0 \cdot 7)\end{array}$ & $\begin{array}{l}495 \\
\quad 9 \cdot 1(0 \cdot 8)\end{array}$ & $\begin{array}{l}322 \\
10 \cdot 4(1 \cdot 1)\end{array}$ & $\begin{array}{l}79 \\
13 \cdot 8(2 \cdot 8)\end{array}$ \\
\hline Ankle & $\begin{array}{l}\text { Number } \\
\text { Prevalence } \\
\text { (95\% CI) (\%) }\end{array}$ & $\begin{array}{l}1763 \\
4 \cdot 1(0 \cdot 2)\end{array}$ & $\stackrel{41}{0 \cdot 6(0 \cdot 2)}$ & $\stackrel{92}{1 \cdot 2(0 \cdot 2)}$ & $\stackrel{142}{2 \cdot 0}(0 \cdot 3)$ & $\begin{array}{l}270 \\
4 \cdot 3(0 \cdot 5)\end{array}$ & $\stackrel{410}{7 \cdot 1(0 \cdot 7)}$ & $\begin{array}{l}439 \\
8 \cdot 1(0 \cdot 7)\end{array}$ & $\stackrel{290}{9 \cdot 4(1.0)}$ & $\begin{array}{l}79 \\
13 \cdot 8(2 \cdot 8)\end{array}$ \\
\hline Wrist & $\begin{array}{l}\text { Number } \\
\text { Prevalence } \\
\text { (95\% CI) (\%) }\end{array}$ & $\begin{array}{l}1430 \\
3 \cdot 3(0 \cdot 2)\end{array}$ & ${ }_{0}^{31} \cdot 4(0 \cdot 1)$ & $\stackrel{95}{1 \cdot 3(0 \cdot 3)}$ & $\stackrel{158}{2 \cdot 3(0 \cdot 4)}$ & ${ }_{3.6(0.5)}^{227}$ & ${ }_{6 \cdot 1(0 \cdot 6)}^{349}$ & $\stackrel{313}{5.8(0.6)}$ & ${ }_{6.6(0.9)}^{205}$ & $\begin{array}{l}52 \\
9 \cdot 1(2 \cdot 4)\end{array}$ \\
\hline Elbow & $\begin{array}{l}\text { Number } \\
\text { Prevalence } \\
\quad(95 \% \text { CI })(\%)\end{array}$ & $\begin{array}{l}1315 \\
3 \cdot 1(0 \cdot 2)\end{array}$ & $\stackrel{21}{0 \cdot 3}(0 \cdot 1)$ & $\stackrel{60}{0 \cdot 8(0 \cdot 2)}$ & $\stackrel{179}{2 \cdot 6(0 \cdot 4)}$ & $\stackrel{296}{4 \cdot 7(0.5)}$ & ${ }_{5.5(0.6)}$ & $\begin{array}{l}261 \\
4 \cdot 8(0.6)\end{array}$ & ${ }_{4}^{137}$ & ${ }_{7 \cdot 4}^{42}(2 \cdot 1)$ \\
\hline $\begin{array}{c}\text { Spine } \\
\text { Back }\end{array}$ & $\begin{array}{l}\text { Number } \\
\text { Prevalence }\end{array}$ & $\begin{array}{l}4262 \\
10 \cdot 0(0 \cdot 3)\end{array}$ & $\stackrel{139}{2 \cdot 0(0 \cdot 3)}$ & ${ }^{380} 5 \cdot 1(0.5)$ & $\begin{array}{l}705 \\
10 \cdot 2(0 \cdot 7)\end{array}$ & $\begin{array}{l}777 \\
12 \cdot 4(0 \cdot 8)\end{array}$ & $\begin{array}{l}939 \\
16 \cdot 3(1 \cdot 0)\end{array}$ & $\begin{array}{l}767 \\
14 \cdot 1(0.9)\end{array}$ & $\begin{array}{l}465 \\
15 \cdot 0(1 \cdot 3)\end{array}$ & $\begin{array}{l}90 \\
15.8(3.0)\end{array}$ \\
\hline Neck & $\begin{array}{l}\text { Number } \\
\text { Prevalence } \\
(95 \% \text { CI })(\%)\end{array}$ & $\stackrel{2539}{5.9(0 \cdot 2)}$ & ${ }^{31} .4(0 \cdot 1)$ & ${ }_{1}^{131} \cdot 7(0 \cdot 3)$ & $\stackrel{349}{5.0(0.5)}$ & $\stackrel{447}{7 \cdot 2(0 \cdot 6)}$ & $\stackrel{657}{11 \cdot 4(0 \cdot 9)}$ & $\begin{array}{l}563 \\
10 \cdot 3(0 \cdot 8)\end{array}$ & $\begin{array}{l}308 \\
10 \cdot 0(1 \cdot 1)\end{array}$ & $\begin{array}{l}53 \\
9 \cdot 3(2 \cdot 4)\end{array}$ \\
\hline
\end{tabular}
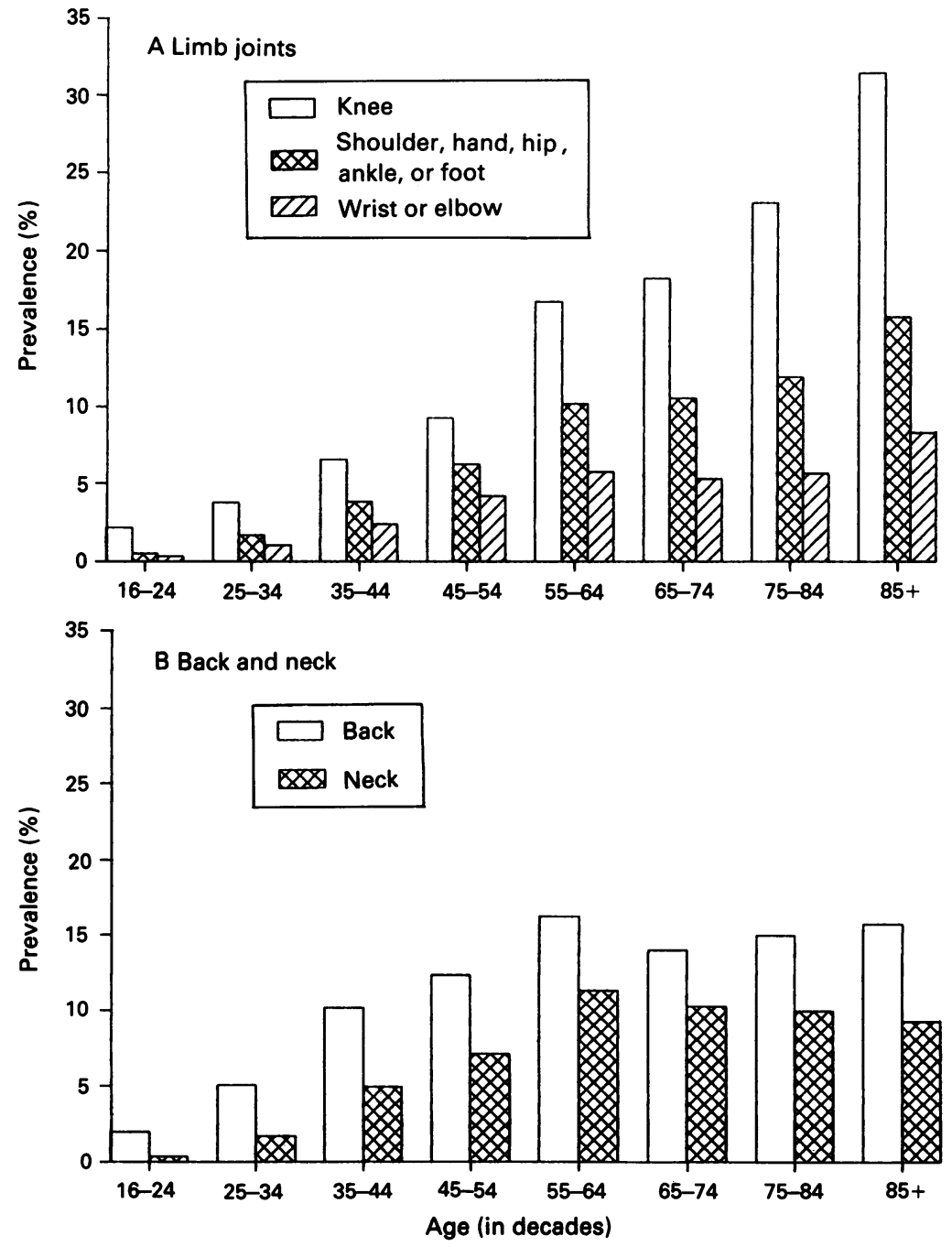

Figure 2 Changing prevalence of joint, back and neck problems with age. problem joints (table 3). In contrast, the increase in the prevalence with age of those reporting seeing a hospital specialist because of these problems was only found up to the 55-64 year decade, after which it was fairly constant. As the prevalence of joint problems, other than the back and neck, continued to rise after this age, this implies a decline in the proportion seeing a specialist in the older age groups.

The overall prevalence of disablement in association with joint problems in the population was $9 \cdot 6 \%$ (95\% CI $9 \cdot 3$ to $9 \cdot 9 \%$ ). A prevalence of $7 \cdot 0 \%(95 \%$ CI $6 \cdot 8$ to $7 \cdot 2 \%)$ was found for reported difficulty, and $2 \cdot 6 \%(95 \%$ CI 2.4 to $2 \cdot 8 \%$ ) for reported dependence; the rates increased with age (table 4). Figure 3 shows the changing prevalence with age of reported disability and dependence for those who reported joint problems. The rate of reporting of disablement increased more steeply with age than that for joint problems as a whole. In the 16-34 year age group only $10 \%$ of those with joint problems reported disablement; this increased to $90 \%$ for the subjects older than 85 years, which is reflected by the hatched area covering $90 \%$ of the bar representing these subjects. For those with disabilities, the ratio of reported dependence to disability also increased steeply with age, so that for subjects older than 85 years, $60 \%$ of those with joint problems were dependent. When adjustments are made so that only those who specifically mention rheumatic disorders as the cause of disability are included, the prevalence of disablement decreases to $7 \cdot 2 \%$ (95\% CI $7 \cdot 0$ to $7 \cdot 5 \%$ ), with $5 \cdot 6 \%$ (95\% CI $5 \cdot 3$ to $5 \cdot 8 \%)$ reporting difficulties, and $1 \cdot 7 \%(95 \% \mathrm{CI}$ 1.5 to $1.9 \%$ ) reporting dependency. 
Table 3 Reported morning stiffness, regular taking of drugs, and seeing a hospital specialist because of problem joints, by subjects reporting joint disorders in the Calderdale population. Estimated number and percentage prevalence by age group (numbers in parentheses give $95 \%$ confidence intervals (CI) when added to and subtracted from the prevalence)

\begin{tabular}{|c|c|c|c|c|c|c|c|c|c|c|}
\hline \multirow{2}{*}{$\begin{array}{l}\text { Reported } \\
\text { result of } \\
\text { joint } \\
\text { problem }\end{array}$} & \multirow[t]{2}{*}{ Occurrence } & \multicolumn{9}{|c|}{ Age group (years) } \\
\hline & & All ages & $16-24$ & $25-34$ & $35-44$ & $45-54$ & $55-64$ & $65-74$ & $75-84$ & $85+$ \\
\hline $\begin{array}{l}\text { Morning } \\
\text { stiffness }\end{array}$ & $\begin{array}{l}\text { Number } \\
\text { Prevalence } \\
(95 \% \text { CI })(\%)\end{array}$ & $\begin{array}{l}3367 \\
7 \cdot 9(0 \cdot 3)\end{array}$ & $\stackrel{79}{1 \cdot 1(0 \cdot 2)}$ & $\begin{array}{l}218 \\
2 \cdot 9(0 \cdot 4)\end{array}$ & $\begin{array}{l}465 \\
6 \cdot 7(0 \cdot 6)\end{array}$ & $\begin{array}{l}568 \\
9 \cdot 1(0 \cdot 7)\end{array}$ & $\begin{array}{l}741 \\
12.9(0.9)\end{array}$ & $\begin{array}{l}673 \\
12.4(0.9)\end{array}$ & $\begin{array}{l}479 \\
15 \cdot 5(1 \cdot 3)\end{array}$ & $\frac{144}{25 \cdot 2(3.6)}$ \\
\hline $\begin{array}{l}\text { Regular } \\
\text { drugs }\end{array}$ & $\begin{array}{l}\text { Number } \\
\text { Prevalence } \\
(95 \% \text { CI })(\%)\end{array}$ & $\begin{array}{l}3889 \\
9 \cdot 1(0 \cdot 3)\end{array}$ & $\stackrel{58}{0.8(0 \cdot 2)}$ & $\stackrel{161}{2 \cdot 2(0 \cdot 3)}$ & $\begin{array}{l}333 \\
4.8(0.5)\end{array}$ & $\begin{array}{l}534 \\
8 \cdot 6(0 \cdot 7)\end{array}$ & $\begin{array}{l}833 \\
14 \cdot 4(0 \cdot 9)\end{array}$ & $\begin{array}{l}1005 \\
18 \cdot 5(1 \cdot 0)\end{array}$ & $\begin{array}{l}801 \\
25 \cdot 9(1.5)\end{array}$ & $\begin{array}{l}164 \\
28 \cdot 7(3 \cdot 7)\end{array}$ \\
\hline $\begin{array}{l}\text { Seen } \\
\text { specialist }\end{array}$ & $\begin{array}{l}\text { Number } \\
\text { Prevalence } \\
\quad(95 \% \text { CI })(\%)\end{array}$ & $\begin{array}{l}4137 \\
9 \cdot 7(0 \cdot 3)\end{array}$ & $\begin{array}{l}140 \\
2 \cdot 0(0 \cdot 3)\end{array}$ & $\begin{array}{l}297 \\
4 \cdot 0(0 \cdot 4)\end{array}$ & $\stackrel{563}{8 \cdot 1(0 \cdot 6)}$ & $\begin{array}{l}723 \\
11 \cdot 6(0 \cdot 8)\end{array}$ & $\begin{array}{l}897 \\
15.6(0.9)\end{array}$ & $\begin{array}{l}875 \\
16.1(1.0)\end{array}$ & $\begin{array}{l}553 \\
17.9(1.4)\end{array}$ & $\begin{array}{l}89 \\
15 \cdot 6(3 \cdot 0)\end{array}$ \\
\hline
\end{tabular}

Table 4 Reported difficulty and dependence by subjects reporting joint problems in the Calderdale population. Estimated number and percentage prevalence by age group (numbers in parentheses give $95 \%$ confidence intervals $(C I)$ when added to and subtracted from the prevalence)

\begin{tabular}{|c|c|c|c|c|c|c|c|c|c|c|}
\hline \multirow{2}{*}{$\begin{array}{l}\text { Reported } \\
\text { difficulty or } \\
\text { dependence }\end{array}$} & \multirow[t]{2}{*}{ Occurrence } & \multicolumn{9}{|c|}{ Age group (years) } \\
\hline & & All ages & $16-24$ & $25-34$ & $35-44$ & $45-54$ & $55-64$ & $65-74$ & $75-84$ & $85+$ \\
\hline $\begin{array}{l}\text { Difficulty } \\
\text { only }\end{array}$ & $\begin{array}{l}\text { Number } \\
\text { Prevalence } \\
(95 \% \text { CI })(\%)\end{array}$ & $\stackrel{2986}{7 \cdot 0(0 \cdot 2)}$ & $\stackrel{23}{0.3}(0.1)$ & $\stackrel{88}{1 \cdot 2(0 \cdot 2)}$ & 213 & ${ }_{5.9(0 \cdot 6)}^{371}$ & $\begin{array}{l}734 \\
12 \cdot 3(0 \cdot 8)\end{array}$ & $\begin{array}{l}884 \\
16.3(1.0)\end{array}$ & $\begin{array}{l}584 \\
18.9(1.4)\end{array}$ & $\begin{array}{l}89 \\
15 \cdot 6(3 \cdot 0)\end{array}$ \\
\hline $\begin{array}{l}\text { Dependence } \\
\text { only }\end{array}$ & $\begin{array}{l}\text { Number } \\
\text { Prevalence } \\
(95 \% \text { CI })(\%)\end{array}$ & ${ }_{2 \cdot 6}^{1110}(0 \cdot 2)$ & ${ }_{0 \cdot 2}^{10}(0 \cdot 1)$ & $\stackrel{14}{0 \cdot 2(0 \cdot 1)}$ & $\stackrel{41}{0 \cdot 6(0 \cdot 2)}$ & ${ }_{1}^{71} \cdot 1(0 \cdot 3)$ & $\stackrel{143}{2 \cdot 4(0 \cdot 4)}$ & $\begin{array}{l}247 \\
4.5(0.6)\end{array}$ & $\begin{array}{l}399 \\
12.9(1 \cdot 2)\end{array}$ & $\begin{array}{l}185 \\
32 \cdot 4(3 \cdot 8)\end{array}$ \\
\hline $\begin{array}{l}\text { Difficulty } \\
\text { and } \\
\text { dependence }\end{array}$ & $\begin{array}{l}\text { Number } \\
\text { Prevalence } \\
\quad(95 \% \text { CI) (\%) }\end{array}$ & $\begin{array}{l}4096 \\
\quad 9 \cdot 6(0.3)\end{array}$ & ${ }^{33} 0.5(0.2)$ & $\stackrel{102}{1 \cdot 4(0 \cdot 3)}$ & $\stackrel{254}{3.7(0.4)}$ & $\stackrel{442}{7 \cdot 1(0 \cdot 6)}$ & $\begin{array}{l}877 \\
14.7(0.9)\end{array}$ & $\begin{array}{l}1131 \\
20 \cdot 8(1 \cdot 1)\end{array}$ & $\begin{array}{l}983 \\
31.8(1.6)\end{array}$ & $\begin{array}{l}274 \\
48 \cdot 0(4 \cdot 1)\end{array}$ \\
\hline
\end{tabular}

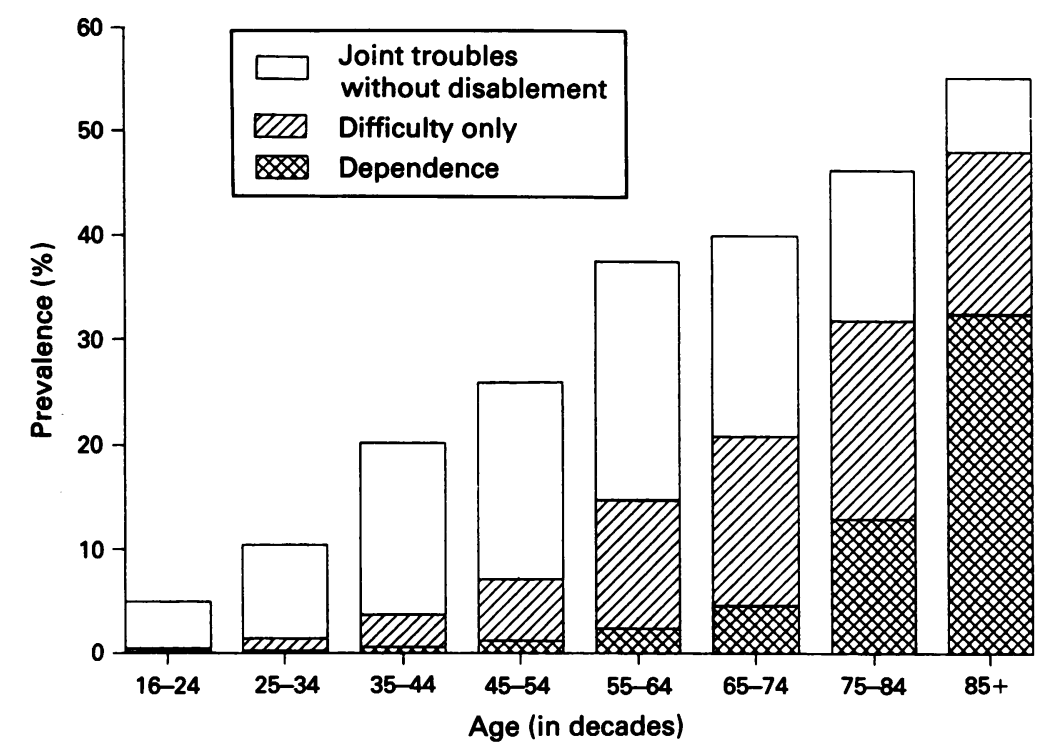

Figure 3 Prevalence of reported dependence and difficulty in activities of daily living and reported joint problems by age. of a sample of the US population aged $25-74$ years gives an estimate of $29 \cdot 7 \%$ for people reporting pain, swelling, or morning stiffness. ${ }^{1}$ The age range in the Calderdale survey was wider; the comparable figure for the 25-74 age group is $25.5 \%$, which is of a similar order of magnitude. Comparison of joint problems by site shows a slightly lower reported prevalence for back and knee disorders in the Calderdale survey. These remain lower even when the difference in the age of the populations is taken into account.

Data from Calderdale are in line with those reported from other population surveys. The US National Health Interview Survey, which is designed to be representative of the US population aged $16-64$ years, indicates that $10.6 \%$ of the population report symptoms of arthritis (pain or swelling in the hip, knee, ankle, foot, shoulder, elbow, or hand). ${ }^{15}$ This figure does not include symptoms originating from the back or neck. In the Canadian health survey the estimated prevalence of reported arthritis, rheumatism, or back or limb and joint disorders in the population aged 16 years and older was $20 \cdot 6 \%{ }^{4}$

There are reasons to suppose that the Calderdale estimates may be conservative. ${ }^{16}$ The data were collected from a household survey where the information about all household members was obtained on the same questionnaire. The reporting of information may thus be subject to a proxy effect as the questionnaire could be completed by one household member on behalf of all others, though we have no indication about the extent of any consultation that may have taken place. As part of our methodological evaluation of the survey we compared responses from households with one adult member only with those from households with two or more adults. ${ }^{16}$ After allowing for 
differences in the age and sex composition of the two types of household, the findings are compatible with a proxy effect in the reporting of joint symptoms. Investigation of the interaction of the two parts of the questionnaire suggested that reporting of important disability had an 'overshadowing effect' on the reporting of joint problems when the questionnaire was completed by a proxy. It is difficult to estimate the magnitude of any proxy effect and to make corrections in view of the very different demographic characteristics of those who live alone and with others. It implies, however, that the findings from this study should be viewed as minimum estimates.

Relatively little is known about the change in the pattern of joint symptoms with age. Other studies indicate that although the occurrence of arthropathies increases with age, spinal conditions tend to have a peak prevalence in middle life. ${ }^{1513}$ This is consistent with the pattern of joint symptoms found in this study, which shows an increase with age in the prevalence of joints symptoms, but a plateau with age for the neck and back.

Although the presence of joint symptoms alone cannot indicate the severity of the effect on the subject, the indications are that the increase in prevalence of symptoms is paralleled by an increase in the extent to which the subject is affected. This is shown by the increase in reporting of multiple joint problems with age. The rate of reported taking of drugs and of morning stiffness also increases in a similar way to reported joint symptoms.

The prevalence of those reporting seeing a specialist because of joint problems does not follow the overall pattern, but declines with age. There may be several reasons for this. In the first instance these findings may reflect a cohort effect. When the current cohort of elderly people first experienced problems with their joints (perhaps as much as 20 years previously) there were few specialists to whom they could have been referred; since then they have lived with their problems as part of 'growing old'. Secondly, it is difficult to know whether it is a real effect or whether it might be a function of factors such as lesser recall with increasing age, or an increasing propensity to under-report consultation as age increases. However, a study in Aberdeen, Scotland, showed that, whereas $35.5 \%$ of people aged more than 60 years reported arthritis and rheumatism, only $19.9 \%$ reported being referred to an outpatient department and $4.3 \%$ being admitted to hospital for these conditions. ${ }^{17}$ Thirdly, data on consultation from this particular part of the United Kingdom may reflect the fact that the level of service provision in rheumatology was only $39 \%$ of the optimum input. ${ }^{18}$ This might affect both the rate of referral to specialists by general practitioners, and, if patients have to travel some distance to see a rheumatologist, then their ability to do so may decline with increasing age.

The overall reported prevalence of disablement, ascertained by a positive answer to any of the questions on activities of daily living, for respondents with joint problems was 9.6\% ( $95 \%$ CI $9 \cdot 3$ to $9 \cdot 9 \%$ ), or $7 \cdot 2 \%$ (95\% CI $7 \cdot 0$ to
$7 \cdot 5 \%)$, excluding those who reported a nonrheumatic cause for their disability. This is of a similar order of magnitude to that found in the population of the USA, although disablement is very differently defined in different studies. Analysis of the US Health Interview Survey suggests that musculoskeletal impairments (chronic or permanent defects representing a decrease or loss of ability to perform various functions) affect about $10 \%$ of the population, and that impairments due to the back or spine are almost half of these. ${ }^{2}$ Reported data from the HANES1 survey allows an estimation that $6.3 \%$ of the population in the $24-75$ year age group have joint symptoms and moderate to severe activity restriction. ${ }^{1}$ The prevalence of rheumatic disorders in the Swedish population aged 16-74 years which are a cause of long term illness, any handicap, or other debility is of the order of $12-13 \%$, and increases markedly with age. ${ }^{9}$

The prevalence of disablement in the Calderdale survey is slightly higher than the recent OPCS survey of disability in Great Britain, which suggests that for adults living in private households the prevalence of disability due to disorders attributable to the musculoskeletal system is $6 \cdot 2 \%{ }^{7}$ It is also much higher than the prevalence of $3 \%$ found in the earlier government survey of handicap and disability in Great Britain (the Harris survey). ${ }^{819}$ Once again, problems arise in direct comparison because of different definitions and different methods of ascertainment of disability. The higher prevalence in the current survey may reflect the fact that our screening questionnaire was made more sensitive to disability associated with the rheumatic diseases by including activities such as combing and brushing hair, and getting out of a low chair. It also attempted to elicit gross mobility in terms of being able to get out of the house without help. The Harris survey screening questions ${ }^{819}$ were more directed to need for personal assistance and to be looked after.

There is a pronounced age related increase in the reporting of disablement in those with joint symptoms. This has been found in other studies of rheumatic disablement in the population. ${ }^{119}$ It is not possible to attribute the cause of the disablement solely to the joint problems, as many people reported more than one medical condition, a fact consistent with the general distribution of comorbidity in the population, particularly in those in older age groups. ${ }^{20}{ }^{21}$ It is, however, likely that the functional consequences of joint disorders contribute to the experience of disablement.

The increasing proportion with age of those reporting both joint troubles and disablement, particularly dependence, is of concern in the context of the aging population. Although the total number of people in the population of the United Kingdom is expected to change relatively little in the coming decades, the proportion of those aged 65 years and older is estimated to increase by a quarter from $15 \%$ in 1985 to $21 \%$ by $2030.0^{10}$ The older age groups contain a disproportionate number of women; the increase in prevalence of joint problems with age is also 
more marked for women. As the proportion of older people in the population increases this will have implications for the prevalence of rheumatic disorders in the population and the provision of care in the community and hospitals. The increasing prevalence of disablement in terms of dependence is of special concern as a large proportion of those who are 65 years and older live alone; at the time of the 1981 census almost a third of older people lived alone and almost half lived with a spouse only. ${ }^{12}$ If the lesser rate of seeking specialist help in those who are in the older age groups is real, this also raises questions about whether these people have had adequate intervention from the health care system which might modify or postpone the onset of disablement.

The increasing prevalence of joint symptoms and disablement with age has ramifications for the provision of appropriate resources, particularly in the light of projected changes in the demographic structure of the population. Guidelines for rheumatological provision may have to be reconsidered as the prevalence rises. It is also likely to affect the work patterns of health professionals caring for people with rheumatic disorders. Awareness of the high increase of joint problems in the population is of importance in planning health services for the rheumatic disorders.

We acknowledge the financial support of the Arthritis and Rheumatism Council and the contribution of the staff of the ARC Epidemiology Unit, University of Manchester, UK (Director, Professor PNH Wood), who worked with the authors to carry out this survey.

1 Cunningham L S, Kelsey J L. Epidemiology of musculoskeletal impairments and associated disability. Am $\mathcal{F}$ Public Health 1984; 74: 574-9.
2 Kelsey J L. Epidemiology of musculoskeletal disorders. New York: Oxford University Press, 1982.

3 Lawrence J S. Rheumatism in populations. London: Heinemann, 1977

4 Lee P, Helewa A, Smythe H A, Bombardier C, Goldsmith C H. Epidemiology of musculoskeletal disorders (complaints) and related disability in Canada. $\mathcal{F}$ Rheumatol 1985; plaints) and rest

5 Wood P H N, Badley E M. Epidemiology of locomotor disorders in general practice. In: Jayson M I V, Million R, eds. Locomotor disability in general practice. Oxford: Oxford University Press, 1983: 3-29.

6 Badley E M, Tennant A. Calderdale health and disablement survey. Manchester: Arthritis and Rheumatism Council for Research, 1988.

7 Martin J, White A. The prevalence of disability among adults. OPCS surveys of disability in Great Britain Report 1 . London: OPCS surveys of disability in Great Britain Report
HMSO, OPCS Social Survey Division, 1988.

8 Harris A I. Handicapped and impaired in Great Britain, Part I. London: HMSO, OPCS, 1971.

9 Bjelle A, Allander E, Magi M. Rheumatic disorders in the Swedish population and health care system. I Rheumatol 1980; 7: 877-85.

10 Thompson J. Ageing of the population; contemporary trends and issues. Population Trends 1988; 21: 18-22.

11 Badley E M. Population projections and the effect on rheumatology. Ann Rheum Dis. 1991; 50: 3-6.

12 Family Policies Studies Centre. Fact Sheet. An ageing population. London: Family Policies Studies Centre, 1984.

13 Jacobsson L, Lindgarde F, Manthorpe R. The commonest rheumatic complaints of over six weeks' duration in a twelve-month period in a defined Swedish population. Scand F Rheumatol 1989; 18: 353-60.

14 Harris A I, Head E. Sample surveys in local authority areas. London: OPCS, 1971.

15 Pincus T, Mitchell J M, Burkhauser R V. Substantial work disability and earnings losses in individuals less than age 65 with osteoarthritis. F Clin Epidemiol 1989; 42: 449-57.

16 Tennant A, Badley E M, Sullivan M. Investigating the proxy effect and the saliency rule in household-based postal questionnaires. $f$ Epidemiol Community Health. In press.

17 Taylor R, Ford G. Arthritis-rheumatism in an elderly population: prevalence and service use. Health Bull (Edinb) 1984; 42: 274-81.

18 Wood P H N. For the want of a horse. Brf Rheumatol 1986; 25: 235-42.

19 Badley E M, Thompson R P, Wood P H N. The prevalence and severity of major disabling conditions - a reappraisal of the government social survey of the handicapped and the government social survey of the handicapped and

20 Chappell N L. Measuring functional ability and chronic health conditions among the elderly: a research note on the adequacy of three instruments. $\mathcal{I}$ Health Soc Behav 1981 ; 22: 90-102.

21 Verbrugge $M$ L, Lepkowski J M, Imanaka Y. Comorbidity and its impact on diasability. Milbank $Q$ 1989; 67: 450-84. 